\title{
LA ESPAÑA VACÍA: DE SINTAGMA A GEOGRAFISMO
}

\author{
TOMÁS CORTIZO A'LVAREZ \\ Departamento de geografía. Universidad de Oviedo \\ tcortizo@uniovi.es
}

Un geografismo disfrazado de sintagma recorre el presente informativo español. La expresión es sencilla, fácil de retener, obvia y oportuna, aunque remite a procesos complejos, dilatados y difundidos en la construcción del territorio por la sociedad. Y tan cercana al sentimiento que no es fácil distanciarse para observarla, incluso no estar de acuerdo con alguna de sus manifestaciones. Hay un núcleo duro de preguntas ¿Cómo no sentir nostalgia ante la pérdida de población en grandes extensiones del territorio? ¿Cómo no solidarizarse y pedir ayuda para quien se queda solo? ¿Cómo orientar el afecto por el terruño cuando se está lejos o se mira desde lejos? Y preguntas sin protector ¿Cómo adaptarse a las nuevas condiciones de la producción y del consumo? ¿Cómo defenderse en la metrópoli sin ofender lo distante? Una pregunta sintética doble: ¿Cómo situarse en la periferia, allí donde se encuentre, y defenderse de la marginación?

Y una cuestión de palabras: lo que se dice es lo que es. La expresión España vacía fue utilizada por Sergio del Molino y ha tenido éxito porque ha prestado conciencia a un sentimiento de pérdida y abandono en el momento final del vaciamiento del campo y de la expansión de los servicios en la ciudad, alcanza su máximo cuando se dice vaciada, como consecuencia de una voluntad inmanente. Campo y ciudad han sido trasmutados a cualidad abstracta y simple, con identidad y capacidad de orientar la acción social; la complejidad de los hechos ha sido suspendida y la expresión se ha convertido en bandera de reivindicación política: las cualidades del geografismo definido por Roger Brunet.

Estas notas deben comenzar por la dicotomía entre la literatura y proceso social. Por mucha autoficción, autobiografía o historia y geografía que se incluya, el ámbito de la literatura y el del análisis del territorio pertenecen a mundos di- 
ferentes y siguen reglas que no son intercambiables, por mucho que vayan en el mismo sentido o en el contrario. Lo mismo que la biografía del creador queda al margen de la valoración de la obra.

Son aspectos tan debatidos que basta con tomar postura para seguir adelante. Tengo anotados tres nombres de estudiosos cuyos ecos han guiado al lector: Raymond Williams, Jon Juaristi y Claudio Magris; si añadimos a los recientemente fallecidos Berger y Steiner... Sabemos que no hay compartimentos estancos y que las ideas fluyen en ambos sentidos y se concretan en el comportamiento de las personas, en las decisiones que toman. Hoy, como ayer, las ideas rigen la acción y ayudan a comprender el mundo: ahora se estrena la serie basada en Patria, la novela de Aramburu, y, en la práctica, la ficción es un hecho más en la práctica social.

Entonces, ¿de qué van estas notas? Atañen a la formulación de un geografismo a partir de un sintagma que afecta al territorio, analizan sus implicaciones y apela a la Geografía; van de ver cómo algo ficcional, intelectual y sentimental tiene efectos sociales a través del sentimiento de pérdida, la melancolía, la irreflexión y choca con las leyes de la Naturaleza y de la Humanidad. En fin, van de adoptar un punto de vista para ver sus conexiones y derivaciones. Y bien pueden ser un capítulo de una Geografía para tiempos de crisis.

El despoblamiento de España, las transformaciones agrarias, el abandono de los pueblos, la inundación de valles, los oficios perdidos son asuntos que vienen de antiguo y sus implicaciones conocidas y la preocupación se ha manifestado en el estudio del folklore o la arqueología industrial. Hoy es un proceso concluido: mis hijos escuchaban de sus abuelos y de sus tíos relatos y descripciones que remitían a un pasado que se prolongaba a lo ancestral, fueran cuentos, comportamientos o prácticas. Para mis nietos serán relatos sin rostro. Yo mismo sabía que no tenían fecha de inicio, pero tardé en ser consciente de que tenían fecha de caducidad.

Lo rural despoblado aparece en novelas y todavía hay oposición a los últimos pantanos y hay quien discute la utilidad de los anteriores. Los mismos que riegan el secano o laminan las crecidas, pero (el texto va cumplido de adversativas) a quién le importa si otros comen fruta o verdura, o como los vecinos ribereños del Sequillo y del Valderaduey lamentaban ante el viajero Torbado, fallecido poco ha, haber perdido el croar de las ranas, pero dormían tranquilos desde que levantaron terraplenes en sus márgenes. Y Luis Mateo muestra lo desgarrador de la contradicción cuando lleva a sus hombres que salieron de la miseria con el regadío a ver el pantano de Barrios de Luna. Benet lo dijo de otra manera. 
Hay unos precursores sin futuro que observaron el proceso, aunque luchaban contra dificultades casi insalvables: o bien las leyes de la Naturaleza que se concretan en el Regeneracionismo de Joaquín Costa, él mismo con detractores desde el punto de vista actual -digamos que estas páginas están en la linde de lo políticamente incorrecto y pocas veces lo traspasan-, con su política hidráulica, sus repoblaciones forestales y su inequívoca vocación de luchar contra las condiciones naturales adversas para los habitantes: campesinos y ciudadanos que todavía pasan hambre. O bien las leyes de la Historia, el proceso no la asignatura como tanto simple confunde: por razones de proximidad citaré al notario de Frómista con su revelador título: Castilla en escombros. Sólo por ignorancia localista el sintagma no ha tenido la fuerza de otro: la España vacía.

Estas páginas inciden en lo literario en la medida en que nutren una corriente de sentimientos que se convierten en argumentos políticos, por eso no perdamos de vista obras literarias que tienen su referente en el campo y en el medio rural. Continúan la tradición de la novela picaresca que tanto se despliega en la ciudad (Sevilla o Madrid) como en el campo (el Lazarillo), pero tienen la ventaja de la cercanía, aunque la primera mitad del siglo XX quede muy lejos dada la fugacidad de las ideas, tanto como la segunda. Juan Sebastián Arbó y su ciclo de Martín de Caretas, López-Barrena y su Martín de Llananzales, incluso el reciente La Pell de la Frontera están ahí.

Cuando hice la reseña de la novela de López y Barrena me pareció que le convenía englobarla bajo el epígrafe novela de la tierra, pues el protagonismo correspondía al terruño y al terreno en un territorio sublimado, luego se lo aplicaría a otras. No había leído lo suficiente para saber que la crítica francesa les aplica el apelativo de roman du terroir, un apelativo que se ha difundido en una sociedad que ha enajenado el territorio en favor de la raigambre: la tierra da buenos frutos.

También son pertinentes los viajes menores, aunque sean de autores mayores: los del histriónico CJC posteriores al de La Alcarria, los de Juan Goytisolo de Níjar y La Chanca, el inédito Juan Marsé de Andalucía, el de Ferrés y Salinas a Las Hurdes, el de Ramón Carnicer de La Cabrera. Y los libros de fotos como el de Müller con texto de Azorín, los de Ortiz Echagüe o el de Hielscher. Y las ilustraciones y reportajes de las revistas ilustradas hasta bien entrado el siglo XX, cuando los ecos de sociedad, el deporte y los espectáculos, jel cine!, desplazan definitivamente al pintoresquismo post-tardo-romántico. $Y$ el folklore toma vida propia.

Y las memorias de tantas personas que han tenido su vida, desde los zagales que acompañaron a los últimos rebaños trashumantes hasta los últimos montañeses que sirvieron en las tabernas del valle del Guadalquivir, o las publicaciones 
sobre oficios todavía activos en 1950: raiers y gancheros, resineros y carboneros, esparteros y cesteros.

Hay otro ciclo de literatura que se ampara bajo el paraguas de ser "adalides de la nostalgia": lo que había de denuncia, de descripción o de recuerdo, ahora todo está subyugado por la melancolía en el sentido que tiene el término en Jon Juaristi. El cambio se percibe como pérdida que altera lo más profundo del ser y del estar, como amenaza que impide vivir con sosiego el presente, por tanto, cuánto mejor se estaba en un pasado que, no por cercano al presente cronológico, estaba lejos de la mítica Edad de Oro.

En fin, el proceso es conocido y los geógrafos lo han estudiado: Del campo a la ciudad está publicada en 1970 y es el título número 71 de aquella colección de Salvat para TVE (1969) que por cinco duros llevó la lectura a los hogares españoles (para el simple, $0,15 €$, el enterado que lo mire en las tablas de valor constante de la moneda). En 1986 todavía era posible hacer como práctica de Geografía Regional un mapa de densidad y variaciones de población para los ocho mil municipios españoles jaquellas inmensas extensiones de España con menos de cinco, de diez, de veinte habitantes por $\mathrm{km}^{2}$ !

Ni los alumnos ni yo dábamos crédito a los resultados con los últimos datos disponibles entonces. Los alumnos coloreaban aquellos mapas a mano sobre los de cada provincia publicados en el Nomenclátor; luego los llevábamos al de España publicado por J. M. Casas Torres. Se perdieron como documentos efímeros, pero hoy pueden verse en pantalla con un par de clics o consultarse sin daño en Ería. Revista geográfica (Delgado y Martínez, 2017) y encontrarse en la prensa diaria, como información inmediatamente accesible.

¡Tan recientes, en la España de los ochenta! La España despoblada y densificada por la emigración y el balance negativo entre nacimientos y defunciones estaban allí: conocíamos las causas, las cifras, las comarcas y las regiones, pero ignorábamos que se denominaba la España vacía y no podíamos adivinar que le seguiría la España vaciada.

Entonces ¿dónde está la novedad? En algo del momento post-post que nos toca vivir, escurridizo para el materialista, pero obvio: en el punto de vista. Acabo de leer Noche y océano de Raquel Taranilla y como me pasó con La pobreza de Antonio Gamoneda me influye en el estilo, no menos el sinfonismo de G. Mahler. La cuestión está en crear un discurso, pues sí, el enrevesado pensamiento francés para decir cosas simples ya está en los manuales, no el de Montaigne, Pascal o Descartes, tampoco el de Voltaire, sino el de Beaudrillard, Derrida, Foucault y tantos novísimos, revenidos al día siguiente. Aunque tengan cita a pie de página. 
Ese discurso se sustenta en la disociación entre los protagonistas y los observadores: unos abandonaron el campo, los últimos se fueron quizá hace treinta años, y otros dicen que el campo está vacío. Y eso se lanza al espacio de las letras como una jaculatoria o se proclama como un mal de la patria que alguien tiene que resolver. Pero nadie de éstos hace del campo su lugar de residencia habitual, por mucha Naturaleza que añore y aquel contenga, desvirtuada por el aprovechamiento del monte y del campo, como ponen de manifiesto los incendios, que ya no se apagan en invierno, sino los administrativos "servicios de extinción de incendios", este verano de 2020 Orense. Después de tanta emigración y evolución en la agricultura y en el modo de vida, se descubre una nueva ambición: el campo tiene futuro. Y, por extensión de magia simpática, la pesca, la mina, los encajes de Camariñas y las alfombras del Corpus Cristi de Castropol, La Orotava, Elche de la Sierra o el siciliano Noto.

Entonces hay que buscar a los responsables de la situación a que se ha llegado y luego a los responsables de invertir el proceso y restituir la situación no se sabe en qué estación de partida en la Geografía del pasado. Curiosamente se va hacia atrás para alcanzar el futuro, pero no se deje engañar la lectora por el anuncio de un Paraíso, pues ese retorno tiene como estación de destino la sabana habitada por el mono que se despioja. Ni siquiera el bosque tropical primigenio. Ojo, en la práctica, esa operación se realiza a base de palabras y de fondos públicos.

Llegamos a un punto en que la situación se instala en campos complementarios: lo social y lo literario tienen su correlato y se corresponden con la opinión y las decisiones políticas. Pero también es transparente en un presente que continúa: un territorio complejo, un boom literario y una empresa diversificada en libros, viajes y prensa. Y el campo se vuelve sujeto del discurso literario, del político y del consumo en un reflujo histórico.

Ahora aquellas Alcarrias, Hurdes, Cabreras, Campos de Níjar se han transmutado en "Teruel existe", Soria sin AVE no es nada, León pierde vecinos, aun con AVE; ¡qué lejos estamos! para no quedarse cortos ¡de todo!, y qué grande sería el Bierzo, el propio León y España entera, si Ponferrada, que no Villafranca, fuese capital de provincia. Diga cuencas mineras y aparecerán cientos de cantores de las cuencas que no se atreverían a bajar al pozo. Ponga fibra óptica y el campo vacío hormiguea con tanto urbano que huye de la epidemia para vivir un nuevo Decamerón. Y por aquí seguimos a la dimensión política del asunto...

De poco vale mostrar que hay un nuevo modo de ocupación del territorio; que hay aldeas sin humo porque nadie sabe cortar leña y el tendido eléctrico está instalado con una potencia inverosímil. Y que los cementerios están poblados por quienes vuelven a recibir un adiós al que no pueden responder y de cada vez 
menos conocidos. Y que los alcaldes tienen que atender las necesidades de agua, alcantarillado, basuras y comunicaciones para una población temporera, pero arraigada en el territorio. Un territorio de ocupación sincopada.

Y vamos a lo literario. Cuando hace tres años, en junio de 2017 anoto el libro de Alejandro López Gándara El viento derruido. La España rural que desaparece digo que pertenece a un ruralismo mágico denotado en la adjetivación, en la amenaza de un enemigo latente que cuando fue escrito era la dictadura franquista, la emigración, el despoblamiento. Las personas están abandonadas y son víctimas de la distancia. Como Soria es el territorio que describe, anoto que solo ellos y nadie más sufren esas condiciones. Un razonamiento común a todos los textos que singularizan un territorio o un grupo social. Las personas son bondadosas, sin fisuras; la belleza del campo carece de quebrantos. ¡Ah, los buenos viejos tiempos!, sin vejez. Cuando me pongo con el texto encuentro que Sofía Ruiz habla en SMODA de un ruralismo mágico en un sentido estricto: piedras que hablan en una novela ambientada en el Pirineo. En una cabriola, el geografismo deviene en metáfora.

Si damos un paso atrás, volvemos a una bifurcación en que la opinión es una alternativa a lo literario, solo como medio para abordar la cuestión pues ambas son manifestaciones de lo mismo. He seguido la opinión publicada en el diario El País, en las páginas de los suplementos de viajes, de literatura y en los reportajes, que han devenido en colaboraciones regulares; menos en la radio y en la tv porque apenas presto atención a los noticiarios, aunque el domingo hay en RNE un espacio dedicado a los pueblos y sus habitantes. La singularidad etnográfica vuelve como rareza alternativa a la vida urbana, menor. Aquellos textos han alimentado la torre de recortes que ahora organizaré.

Entre ellos destaca el artículo de Javier Rodríguez Marcos en Babelia de 9-II2019 "Campos de batalla"; está dedicado a "la literatura sobre el mundo rural, [que] vive un renacimiento editorial. La generación de la crisis mezcla memoria personal, crítica al capitalismo y reivindicación feminista". María Sánchez ocupa la portada a toda plana ante un rebaño de ovejas, es veterinaria en Córdoba, meses después es retratada con "chaqueta de YERSE, jersey de DESIGNERS SOCIETY, Pantalón LEVI'S y botas de BLUNDSTONE, junto a Lorena Álvarez con jersey de COS, pantalón de SÉZANE y botas de BLUNDSTONE” en reportaje de Almudena Ávalos con fotos de Ximena Garrigues y Sergio Moya.

Es autora de Cuaderno de campo y Tierra de mujeres; con foto de Alejandro Ruesga; ahora publica Almáciga, sobre las palabras del campo, está sobre la mesa pendiente de lectura; de Rafael Navarro es La tierra desnuda y Santiago Lorenzo con Los asquerosos de Uly Martín. Otros títulos resaltados son los de Emilio 
Barco: Donde viven los caracoles; Pilar Fraile: Las ventajas de vivir en el campo y Elvira Valgañón: Invierno. El autor hace una semblanza de cada libro y salen inevitablemente Julio Llamazares y Sergio del Molino, más el John Berger de Puerca tierra (pero no el de Lila y Flag o Una vez en Europa) e Intemperie de Jesús Carrasco.

El 30-III-2019 Julio Llamazares publica su colaboración sobre la España vacía y hay un artículo sobre el tema y el reportaje de RNE habla de la España vaciada, una expresión que ya utiliza María Sánchez por oposición a vacía: "en los pueblos hay mucha gente haciendo cosas: agricultura respetuosa con el territorio, ganadería extensiva, gente conectada gracias a internet. Muchas mujeres...". Una discrepancia que también abarca las ideas de Sergio del Molino, ella es militante y él es diletante.

El 31-III-2019 hay una marcha de la España vaciada, un giro que connota la voluntariedad del proceso, por tanto, de la búsqueda de responsables y el resarcimiento del daño. No olvidemos este binomio. El 15-II-2020 en la reseña del libro Los países de Marie-Hélène Lafon se utiliza el concepto de roman du terroir. En fin, buscando bibliografía para documentar el texto sobre piedras de molino para mi libro de los oficios, encuentro un artículo sobre Llamazares y el ruralismo que ahora cuando escribo desconectado no puedo citar.

No importa, Julio Llamazares ha decidido hacer del pasado pluscuamperfecto y del mundo rural actual su motivo de vida en su proyección pública: en la novela y en la opinión. No olvidemos que otro leonés ilustre, Luis Mateo Díez y su páramo de Celama, viven el mundo rural de otro modo. Y Miguel Delibes que, de Las Ratas, Castilla habla, Los santos inocentes y sus títulos sobre la caza y la pesca, pasa al discurso de recepción en la Real Academia Española, donde en 1975 resalta el ataque a la Naturaleza. En la obra de Julio Llamazares late la nostalgia y la pérdida: sea en Lluvia amarilla, la fundacional, o Memorias de cine mudo. El pantano del Porma inundó Vegamián, el pueblo donde nació, aunque podía ser el poblado de Bárcena a donde fueron a vivir los vecinos de la aldea inundada por el pantano, y muchos más bajaron de las aldeas de montaña y vieron el cielo en aquellos cuartales llano y con riego; su padre era maestro, por tanto, estaba sujeto a traslados; aquello, no esto, marcó su existencia literaria y de opinión, hasta el punto de que en una entrevista sobre su Memoria del agua traslada el sentir de la novela a su opinión, sin matices ni cortafuegos: opina lo que sienten sus personajes. Cuando menos, es una actitud sospechosa de que pueda ser cierta pues ajusta sus pautas de vida a la fabulación. Pot ser!

El autor del texto fundacional que acuña la expresión es Sergio del Molino en La España vacía. No encuentro referencias concretas en la libreta de trabajo, sí 
sugerencias y llamadas a las publicaciones mencionadas al comienzo de este texto, quizá porque están en el propio libro y en la libreta de lecturas. Vamos allá. La anotación es del 8-IX-2016, pero su lectura transcurrió en un paraje y compañía singulares: en la travesía en el Creoula entre Avilés-Porto-Lisboa. Antes habíamos pasado de Gijón a Brest, con Ramón Alvargonzález, Baldomero Argüelles y Manuel; y rumbo a Brest improvisé la charla sobre el "Sinus cantabricus, el mar de Castilla", un mar de comercio y nada belicoso. No entusiasmó a los instruendos embarcados y su falta de atención dio lugar a que el ingenioso Sabas les denominase como destruendos. Quizá porque también era un mar de guerras.

Me atengo a las notas de entonces para este comentario. En la libreta anoto que ¡buena la hice leyendo a R. Williams! Siempre hay una frase que se ajusta a una lectura, incluso dos: el regreso del nativo o lo difícil que es discrepar con el sentimiento que uno comparte. Leído en alta mar, frente a la Costa da Morte, este libro adquiere otra dimensión porque uno está tentado a saber tanto como el autor y, por carácter, obligado a discrepar. Le gustó a AMM. El autor, de un modo muy lúcido, repasa tópicos sobre España, que hoy da la casualidad que está vacía: Las Hurdes, Fago, las novelas neorrurales, enumera los elementos de "nuestra propia leyenda negra interior", el carlismo como expresión de lo rural profundo. Ha hecho una buena recopilación de temas y los envuelve con un papel que tinta el tratamiento. Digo que veré como hago la reseña para Polígonos. Nunca la escribí, sí la de La pell de la frontera.

Había olvidado que no hice anotaciones en el libro y sí en una ficha, demasiado pocas y tan escuetas que ahora es difícil interpretarlas: ¡cuidado con las perogrulladas! al opinar sobre los datos y los hechos, podemos sentir, pero no debemos cargar las tintas; ¡cuidado con el pasado! porque ni es inteligente ni democrático, pues citar a alguien de 1924, Iñiguez, en plena época determinista, es duro. El propio autor retoma su argumento y le da la vuelta en la pág. 53: "propongo un viaje... empezaré repasando mitos...". O sea, la búsqueda de los orígenes y anoto: Arma virumque cano, Troiaque primus ab oris. Debía ser el ambiente en la navegación porque todo son avisos: ¡cuidado con confundir la poesía con el pan de cada día! A santo de qué párrafo se me ocurrió esto. Sin embargo, el siguiente está asociado con Fago: cuidado al escribir sobre procesos complejos: cabalgar sobre tópicos, cuentas hechos y te recreas en la suerte y en la culpa hay culpables y reproches.

Al final me pregunto dónde están Américo Castro y Sánchez Albornoz, Domínguez Ortiz y Salomon, Perez y Elliott, por poner unos ejemplos que hablaron de las cosas de España; y el propio Ford. Yo mismo renuncio a citar a Manuel de Terán, a Casas Torres y tantos geógrafos que publicaron su trabajo en las revistas 
de geografía (Estudios Geográficos) y libros; siguen siendo un conocimiento gris a pesar de estar en las bibliotecas. Son contemporáneos del cambio territorial y social y su contenido se encuentra en el primer capítulo de La España vacía.

Sin embargo, sí hago una referencia en el diario de a bordo el 25 de agosto de 2016 en las islas Cíes: al atardecer comencé la lectura de LEV y me doy cuenta de inmediato que lo hago con prevención, sino con prejuicio, quizá no sea una lectura para hacer navegando... Dos cosas: por un lado, la sombra de Gargoris y Habibdis y la interpretación mágica del territorio y de sus procesos, de las gentes, sus miedos, sueños y querencias; por otro, la sustitución de la alabanza de aldea por la añoranza de lo que ocurre en otros países.

Y, en un pensamiento triádico, la complejidad del proceso y su variedad territorial, desde la ocupación temporal hasta el abandono absoluto; es curiosa esta voluntad de adoptar un punto de vista alejado (Paul Virilio diría de Dios) desde donde se observan todos los lugares, todas las gentes y todos los tiempos. Veremos cómo evoluciona... Estaba en el comienzo del libro cuando anoté este párrafo, por eso no podía saber qué densidades y qué lugares alcanzaba esa $E s-$ paña vacía. Tampoco podía adivinar que la España vaciada incluiría capitales de provincia incluidas en otro paradigma, las ciudades medias. Y el geografismo se adentraba en un territorio abierto.

Dejemos aquí su germen literario (en el estilo del Pinker de La tabla rasa), sus antecedentes y extensiones y veamos cómo este fantasma ocupa un lugar en el ser y el estar de lo español de comienzos del siglo XXI a través de las noticias, reseñas y colaboraciones y salta a la acción política. En este punto me disculparán la autocita, viene del capítulo "El territorio, ¿un tirano?" en Los paisajes de la acción: "En este contexto, decir que "Teruel existe", o Baiña o Caleao, es delicado por cuanto plantea al político la cuestión de gestionar las contradicciones que surgen en la acción entre Naturaleza y Territorio, proceso y voluntad de manera que no sea un tirano convirtiendo un territorio fragmentado en protagonista de la Historia. Y librando con bien y eficiencia la tiranía del Territorio. Quien lo consiga recibirá, sin duda, el reconocimiento de la sociedad, dueña de su destino y su territorio... A finales de 1999, una campaña lanza la proclama de que "Teruel también existe", con el consiguiente cabreo de quienes teníamos la esperanza de que nos aguardase libre de los bárbaros de fin de semana. El Maestrazgo ya está en el circuito de paisajes con encanto construidos por El País, lo cual no es poco.".

Con lo cual volvemos a la trilogía de los hechos emparedados entre la opinión y la acción. Un preámbulo tan largo para hablar de los hechos: la opinión como motor de una idea: Teruel existe y la España vacía-da y sus mentores; la dimen- 
sión política y el efecto El Bierzo-Arán y la madre del cordero: las periferias en busca de su cuota de centralidad en un vertiginoso proceso centrípeto.

En un mar de recortes y más recortes, de prensa, todo es bueno para el convento: cocina, anuncios, reportajes, pero seguimos anclados en el mismo punto. Hay que definir las dos realidades paralelas que se retroalimentan: la de los literatos dirigida a los lectores y la del territorio perdida en el vacío de las publicaciones, todavía relegadas al mundo académico, salvo catástrofe y titular de prensa. Y llega el momento crítico: la fusión entre la opinión en prensa a través de los reportajes y los anuncios, en los que es indispensable adoptar un tono de desastre; la acción política en forma de promesas, subvenciones y elecciones; la acción política en forma de reivindicación, sean manifestaciones o reclamaciones de representantes para una circunscripción y las nuevas ideas sobre el territorio: periferia, transformaciones económicas con daños sociales.

El 19 de marzo de 1999 Juan G. Bedoya informa en El País con datos de la revisión padronal de 1 de enero de 1998 que siete regiones han perdido población en los últimos tres años en una España de 39,8 millones de habitantes. Con más detalle: cinco provincias en Andalucía, Aragón, Asturias, Cantabria, CastillaLeón excepto Valladolid, dos en Castilla-La Mancha, Cáceres, Galicia, Vizcaya y La Rioja. Quizá en otra información el autor suba un peldaño en la escala del territorio para descubrir que esa evolución, que todavía no tiñe de dramatismo, tiene un sesgo más grave: se está produciendo un reajuste de la población en el territorio en justa correspondencia con la concentración de las actividades económicas, de manera que algunos municipios pierden población o no la retienen, entre ellos algunas capitales de provincia o las ciudades importantes de cada una. ¿O somos víctimas de la compresión del tiempo y adelantamos a toda velocidad a los hechos?

A comienzos del 2000 no hay duda de que España necesitará inmigrantes, 12 millones hasta 2050 según la ONU, unos 240.000 al año. En ese momento, la política del gobierno es admitir un contingente de 30.000 personas procedentes de países no comunitarios, aunque los empresarios piden ampliar la cifra y contratar como temporeros; pero la cifra de solicitudes para trabajar legalmente triplica esa cifra, según información de Carlos E. Cué. En estas fechas, la inmigración todavía era baja y, pese a las previsiones alarmistas a largo plazo, no alteraba la política sobre la localización de la actividad en el territorio ni la actitud de los españoles y españolas ante ciertos trabajos. Por entonces colaboraba semanalmente en La Voz de Asturias y escribía que ser español acabaría siendo una categoría socio profesional, que la opinión daría por natural e indiscutible; en palabras de la tierra "este trabayu nun ye pa mí, ni pal mi fíu y menos pa la mi muyer". 
Pero ya hay detalles que indican una tendencia divergente: Lydia Garrido informa el 6 de abril de 2001 que "Sot de Chera se resiste a morir": el ayuntamiento ofrece casa y trabajo a las familias que lleguen con hijos. Esta peculiar repoblación aparece aquí y allá, unas veces asociada a una escuela que no se cerraría con un par de niños más, otras a la atención a unos ancianos envejecidos. Y cada vez son más los trabajos para los que no se encuentran obreros españoles, sean temporales o fijos, en el campo o en la ciudad, en los servicios en el campo o en los urbanos. Volveremos con otros posibles modos de repoblación. Por primera vez en la historia, la vejez no es sinónimo de penuria, sin embargo, su atención ha sido rehusada por la población activa española en una proporción que no se compadece con la "necesidad de trabajo", digo de empleo.

Años después, el 6 de octubre de 2019 María Martín informa desde Soria que "la provincia más deshabitada de España busca extranjeros para cubrir los puestos que no quieren los españoles". Nada menos que para La Hoguera en Pedro Manrique, donde los listos, ahora jubilados, se hicieron profesores y los tontos, millonarios haciendo chorizos, según testimonio de un profesor nacido en ese lugar. Pero este es una muestra de los innumerables ejemplos de apelación a los emigrantes, que ya solo pueden ser extranjeros para la recogida de la fresa, de la manzana, del melocotón, de los melones, de los ajos; para el pastoreo de un rebaño de ovejas o la construcción y mantenimiento de los edificios.

En la práctica es una muestra del cambio que se ha producido en España, a la que no es ajeno el despoblamiento: de la generalizada emigración estacional para las labores agrícolas, a veces con restricción de movilidad para reservar los jornales a los del propio municipio, a la llamada a los extranjeros mientras los españoles están pendientes del paro, de las peonadas o de los contratos apalabrados. $\mathrm{O}$ en casa tramitando un subsidio. $\mathrm{Y}$ es que poner los productos en la tienda al precio más bajo, manteniendo márgenes y beneficios, conlleva unas condiciones de los trabajadores inadmisibles por infra-infra: en los salarios, las jornadas, el alojamiento o la atención sanitaria, como se ha puesto de manifiesto en Huesca y Lérida durante este verano ante el rebrote de la pandemia de covid-19 y se denuncia año tras años en la campaña de la fresa en Huelva, menos con las mujeres marroquíes contratadas en origen que con temporeros. Y denuncian los sucesivos informes de las organizaciones humanitarias españolas (con Cáritas a la cabeza), la prensa con la regularidad del calendario de las cosechas. O el singular observador internacional., tan cercano al pintoresquismo de la leyenda negra.

"Por favor, no la llamen España vacía" escribe Josefina Gómez Mendoza el 11 de octubre de 2019 y de un modo genérico califica el concepto de demasiado genérico y aboga por "políticas productivas y medio ambiente, se debe reconocer 
a la conservación y a los usos sostenibles su valor económico y de oportunidad". Pero estamos divagando en nuestro argumento. Y perdido el hilo. Ya no se trata de los hechos, conocidos hasta el detalle, tampoco de los motivos: que las personas vayan a otro lugar es una decisión individual, impedir o pedir que se vayan es una decisión colectiva, política. Y no se olviden las nuevas formas de ocupación del territorio que ponen en entredicho el vacio estadístico. Sin embargo, hace falta una política para el campo.

Bien, estadística en mano, una parte de la población vive en una proporción minúscula del territorio, lo cual no afecta al campo, pero a la inversa, sí le afecta que una parte del territorio no tenga población estadística: el $53 \%$ tiene una densidad menor a los 12,5 habitantes por km cuadrado. Añadir que abarca al $48 \%$ de los municipios nos introduce en la magia política, pues un mapa con más de 8.000 municipios sólo se sostiene desde el punto de vista de la "identidad", tan delicuescente como interesado.

Corto y cierro. Cansado. Esta no es la cuestión que ahora se plantea: la construcción de una opinión a partir de un hecho incuestionable. Almaceno decenas de colaboraciones del diario El País y El País semanal. El 30-III-2018 Max le dedica su trampantojo en forma de enigma de la esfinge al caminante: "Por la mañana rocío, al mediodía calor... Empieza por 'la'. ¡La España vacía! responde el caminante. Julio Llamazares habla por activa y por pasiva de la despoblación de las tierras de España y emplea el tono de una llamada de socorro del náufrago a la vista de la orilla acantilada y sorda. Asiste en Zaragoza a la presentación de un libro editado por el Gobierno de Aragón sobre la despoblación; con ser uno de los adalides de la opinión, se desmarca y dice que "mientras los gobernantes hablan de soluciones, quizá porque no las hay y, si las hay, por su coste político, escritores y artistas se limitan a constatar la inevitabilidad del fin, a cantar la elegía de un mundo que se termina delante de nuestros ojos llevándose con él parte del país".

Luis Alegre también da cuenta de La España vacía y aprovecha para mencionar Réquiem por un campesino español de R.J. Sender y La Vieja de J. Antonio Labordeta y El extraño viaje de Fernando Fernán Gómez. Otros títulos también sirven para insistir en el abandono: Los últimos. Voces de Laponia, Donde la vieja Castilla de acaba de Francisco Cerdá y Avelino Hernández respectivamente. Como ideario y como tema está bien definido y es utilizado para "caldear el ambiente", así en agosto de 2017 el diario El País encarga a Sergio del Molino una serie de reportajes, que no seguiremos. Los geógrafos han estudiado el territorio, aunque su aportación no sea reconocida, sin duda, porque carece de interés periodístico, como tanto conocimiento gris que yace en las publicaciones académicas, aunque siempre alguien descubre la redondez de la rueda. 
Por eso aquí, lo dejamos al margen e insistimos en la opinión y sus consecuencias.

Llegamos al momento de la fusión crítica en dos versiones de la práctica: ¿qué hacemos con el territorio vacío-vaciado? o ¿qué partido podemos sacar de él? Alcanzamos el momento en que el Teruel existe de 1999 se ha trasmutado en un diputado en el parlamento, a la negociación de apoyo para la formación de mayorías con minorías minoritarias, a la entrega de una partida de dinero.

Pero no hemos llegado al descubrimiento de que ni la Historia ni la Geografía son democráticos, lo cual nos lanza a la cara otra cuestión latente: la representación parlamentaria no sigue el principio de la ciudadanía sino el del territorio. Y se da la paradoja, democrática, de territorios vacíos sobrerrepresentados y ciudadanos hacinados infrarrepresentados. Pero hay una razón imaginada que sostiene la situación: atender desde cerca las necesidades de los votantes; en consecuencia, los votos valen lo que se acordó que valga el territorio, no el número de personas.

Por la misma razón, otros territorios aspiran a ser circunscripción. El domingo 16 de febrero de 2020 "casi la mitad de los 125.000 habitantes de la ciudad de León salieron a la calle exigiendo inversiones y más autogobierno para frenar su decadencia económica y demográfica", informa Sonia Vizoso. También hubo marchas en Ponferrada y Villablino, el reportaje de una semana después se ilustra con una foto de los dos líderes sindicales, organizadores de la protesta y la de la manifestación con una foto de J. Casares que insiste en el tópico: "iQue maravilla, León sin Castilla!", bueno, dicho con el león y el castillo de sus escudos. Viviendo y escribiendo en Asturias, el argumento es sencillo: primero los salarios, luego las jubilaciones, luego las subvenciones y ahora los fondos para la resurrección de la vida de un territorio en este caso ligado al yacimiento.

No insistimos, si la independencia de León (¿qué León?) garantiza la mejora de los leoneses, veremos qué ocurre en El Bierzo, en Arán o en Cartagena. Y en tantos territorios irredentos.

El problema es serio y más importante de lo que piensan los poderes públicos en todas sus encarnaciones (ocho mil municipios no son suficientes para que el político esté cerca del ciudadano. El 15 de setiembre de 2018 Sergio del Molino dice que "la España vacía alza la voz", está tan prisionero de su propio hallazgo verbal que le impide mirar y ver: "hay una España sin AVE... los habitantes de la España vacía (en torno a diez millones)". Ahora ya la opinión se ve desbordada por la acción. El viernes 4 de octubre de 2019 "miles de ciudadanos de las 23 provincias más despobladas del país se sumaron a las concentraciones de silencio convocadas para exigir atención a la Administración". Es una iniciativa de 
la Coordinadora de la España Vaciada, agrupa a 121 organizaciones surgidas "a partir de la marcha a Madrid del pasado 31 de marzo".

Y se suceden las informaciones.

Un Centro de Competencias Digitales (CCD) de Renfe se traslada a Teruel, en justo premio a su tesón iy a su electorado! El conjunto de estas actividades (automatización inteligente de procesos, operación gestionada de infraestructuras IBM, almacenamiento en la nube, aplicaciones móviles, sistemas de negocio y gestión de relaciones con los clientes) creará 400 puestos de trabajo en los lugares donde Renfe tiene infraestructuras disponibles. Informa Ramón Muñoz el 16-IX2020 en El País. De momento, entre 50 y 60 en Teruel. En la práctica, es parte de la Estrategia Nacional frente al Reto Demográfico dependiente del Ministerio de Transportes, Movilidad y Agenda Urbana. ¿Quién se acuerda de aquel primer Plan de Desarrollo para 1964-1967, con sus Polos de Promoción y Desarrollo, sus Polos de Descongestión, sus Zonas de Preferente Localización Industrial y sus Planes Especiales? Felipe Fernández estudió el de Asturias. Buscaban descongestionar las áreas urbanas y dispersar la industria por el territorio, el ejemplo de Aranda de Duero es proverbial.

Incluso localidades grandes de innumerables municipios, ese anacronismo incrustado en la gestión política del territorio, se quedan sin oficinas bancarias ¿qué se hizo de aquel anuario de Banesto, paradigma de la información a gran escala?; se cierran escuelas, cuarteles, dispensarios, iglesias al mismo tiempo que fenecen los últimos que los abrieron y disfrutaron de los primeros en aquella España superpoblada, trabajadora del campo, habitante de aldeas sin agua, ni luz, ni teléfono, ni carretera, ni médico, ni maestro porque habían sido depurados y todavía no se había puesto en práctica el Plan de Edificaciones Escolares de escolar en 1959.

Y el geógrafo no encuentra palabras para explicar la rugosidad del territorio y lo peculiar de su encaje de escalas. Por ejemplo, que los ciudadanos tengan la misma facilidad de acceso entre cualquier punto, como si la montaña, el río y la propia distancia euclidiana fueran una ilusión, un trampantojo; que los ciudadanos que lo habitan tengan "lo mismo" que los habitantes de la ciudad, como si las condiciones geográficas perteneciesen a la misma categoría que los valores y derechos sociales, pues éstos son abstractos, aquellas son materiales. España y cualquier país atenderá todas las necesidades que tengan sus ciudadanos por igual en cualquier lugar que se diga. Ninguno estaremos entonces para verlo, lo cual no impide hacer un bucle con el tiempo para alimentar el argumento y, mientras tanto, sentirnos "abandonados y despreciados". 
Y primer final. Un discurso que apela a la nostalgia, sin profundidad, ni conocimiento conduce al populismo más elemental. Las elecciones celebradas en 2019 han tenido como resultado un peculiar balance en la España vacía: dado que los escaños se asignan por provincias, los dirigentes buscaron ganar el tercer o cuarto escaño de cada una; ese resto una vez descontados los del primer y segundo partido, propio del bipartidismo. El resultado del 20 de noviembre fue demoledor: Ciudadanos perdió los 13 diputados de las provincias con menos diputados y Vox ganó ocho, con la particularidad de que, si Cartagena fuera circunscripción, este partido obtendría diputado.

Así pues, a un discurso irracional le corresponde una elección visceral.

Segundo final: las escalas en el encaje de las periferias. Preparando la clase de Geografía Regional de España aprendí una lección: algunos lugares actuaban como centros comarcales que atendían buena parte de las necesidades de una población mayoritariamente rural y con un sistema de comunicaciones basado todavía en los desplazamientos a pie. Hablo del Valladolid de 1892 cuyo censo de votantes permite conocer los servicios elementales de villas como Medina del Campo y Medina de Rioseco, Iscar o Peñafiel. Con independencia de su tamaño, tenían el mismo equipamiento: su boticario, su médico, su juez, su notario, sus parroquias, su almacén, su feria, su mercado... su secretario de ayuntamiento. El campesino podía pasar su vida sin pisar la capital de provincia nombrada ya cincuenta años antes (no así el hacendado, que podía pleitear en la Audiencia).

Ese tipo de villas desempeñó su papel en todo el territorio español durante los sesenta años siguientes, aunque cada vez más relegado en la medida en que mejoraban las comunicaciones hasta ser eclipsado por la capital provincial, cuando el campesino y el vecino de esa antigua capital comarcal acuden directamente a la capital o a otra ciudad. Ellas mismas encajadas como una muñeca rusa en una red urbana cada vez más jerarquizada en un territorio todavía organizado en tela de araña sobre la que dominan unas pocas metrópolis convertidas en nodos de una red urbana. A escala mundial la imagen adquiere un aire de comic futurista: una estructura formada por muy pocas torres Eiffel con las cúspides enlazadas por rayos cósmicos sobre un fondo azul negro.

Por su parte, en 1902 más de la mitad de la población de la ciudad de León era forastera, hoy la propia ciudad pierde población (Sergio Tomé), pero dejemos los datos concretos para la erudición. En los últimos diez años, la reserva de población rural se ha agotado y el sistema económico ha creado en el territorio español dos remolinos mayores que absorben toda la energía que está a su alrededor. Recursos y población, talento en inversiones se concentran en muy pocos nodos con una diferencia de escala planetaria desconocida hasta ahora: Madrid, París, 
Milán, Londres, Nueva York y, en un exceso, tiende a un centro único. Ahora Medina del Campo ya no compite con Valladolid, ni León con Ponferrada, ni Almería con Sevilla, ni Guadalajara con Madrid.

A hora esa fluidez entre espacios y nodos contiguos ha desaparecido y la cuestión es situarse en la red mundial de información y de poder. La manifestación más palpable de las nuevas condiciones del territorio es la pérdida de población de las propias ciudades, unas veces por recolocación de vecinos dentro de su área metropolitana por nuevos usos del centro, la presión del turismo, las oportunidades en núcleos próximos, pero otras es consecuencia de la concentración. Por ejemplo, la carrera de Madrid tuvo como etapas la ampliación de Barajas, la segunda fase de la Operación Chamartín y la desregulación (menos impuestos, menos servicios públicos, precariedad laboral); el más Barcelona, con la ampliación del Prat, aunque paradójicamente para tener menos turismo.

Enfrascados en la gran escala de los diferentes aspectos de las España vacía (pérdida de población en el medio rural y el urbano o diferencias y competencia entre territorios) este movimiento nos ha sorprendido, su amplitud nos abruma y su generalidad nos desconcierta. En un abrir y cerrar de ojos, en el tiempo que precisa la generación de relevo para formarse y antes de sustituir a la anterior, han cambiado las condiciones en la relación social: los cambios económicos se producen a gran velocidad y son radicales, sin tiempo para asimilar y adaptarse a la novedad, y la relación con el territorio ha roto la proporción de escala, la comarca, la provincia, el Estado se han fundido en un espacio planetario.

En un giro de la espiral hexana, ese territorio material y rugoso, jerarquizado y continuo reconocible, pasa a ser un espacio horadado dominado por las relaciones entre los nodos a través de la MMM por donde circulan las ideas y la innovación, el dinero y el poder. Un paso más y entramos en un espacio sustraído dominado por la información: "el habitante no puede hacerse invisible, pero oculta los espacios de tránsito convirtiéndolos en no-lugares. O rompe con los modos tradicionales de la producción, se aísla en la multitud o en un campo invisible". El final es el fin: el espacio isotrópico, puro y desnudo en el que la materia viaja como energía, a la velocidad de la luz.

Regresemos al tiempo presente, a un territorio todavía reconocible según las coordenadas cartesianas, aunque deformadas cada vez más por la gravitación newtoniana -antes de ser puramente cuánticas-; y a una sociedad con memoria del pasado reciente y ligada a territorios de vida concretos; con memoria y nostalgia, con sueños y ambiciones. Y con intereses. En esta situación, unos sacan el pendón, otros se ponen los chalecos amarillos para protestar; cada uno defiende lo suyo, pero a escalas incompatibles: unos lo material concreto, otros el rendimien- 
to financiero. A la gestión de la España vacía la nueva situación le viene grande y no había visto que, mirando al ombligo del territorio o del sector económico, se le venía encima la globalización.

Nosotros mismos asistimos al proceso y lo miramos desde fuera iquién tuviera la inteligencia de Guilluy para ver lo que nos estaba ocurriendo y en vez de encontrar el sintagma de la España vacía hubiéramos tropezado con las consecuencias de la desregulación, antecedente de la globalización, con la España periférica.

Tercer final. Celebraciones silenciosas recuerdan los cincuenta años del paradigma "crear valor para los accionistas", con Milton, Margaret (1979-1990) y Ronald (1981-1989) al frente de unos seguidores "obligados" por la corriente de "todo el sistema económico orientado a generar beneficios" para repartir como dividendo y retribución de la élite. Por un lado, la desregulación de las relaciones laborales y la liberalización del mercado sentaron las bases de la globalización y de un consumo desconocido en su desmesura y generalidad; por otro, el "menos Estado" con la privatización de los servicios públicos o su relegación (sanidad, educación, pensiones, subsidios, atención a los marginados) canalizó una parte cada vez mayor de los recursos generados por la sociedad hacia menos propietarios. Cualquier cifra que se dé sobre la distribución de la renta entre el trabajo y el capital o distribución de éste entre empresas, fondos o conglomerados es sustituida al poco tiempo por otra en la que ha crecido la diferencia en contra del número mayor de personas, bien por percepción directa o distribuida a través de los servicios públicos.

Es curioso cómo los textos evitan las palabras antiguas del análisis marxista que vienen como anillo al dedo cuando se observan los hechos. Una acumulación del capital en pocas manos concentra las decisiones, la distribución de los recursos y, en lo que atañe al territorio, los lugares del poder. Ahora, siguiendo el sentimiento, dejamos a un lado la clase social y abandonamos el argumento de las relaciones sociales o nos centramos en el territorio y lamentamos cómo se localizan los habitantes, las fábricas y las decisiones. Christophe Guilluy nos muestra (La France périphérique) que no es posible tal separación, por cuanto los sectores económicos en declive arrastran a los territorios y a las personas y los relegan en la nueva organización del espacio y de las relaciones sociales.

Por eso, el problema no es la España vacía, tampoco la vaciada; la amenaza es general y atañe a la sociedad y al territorio. En consecuencia, ya no se trata de la igualdad de los ciudadanos "allí donde se encuentren" mirando para las serranías sorianas o la dehesa extremeña. Hemos descubierto que hay ciudadanos residentes en centros de poder que están a la misma distancia de los servicios y 
de los recursos que los habitantes de la Siberia española o cualquier comarca o territorio cuya denominación geográfica es sufrir algún adjetivo chusco.

Saben de ello la fracción de jóvenes mal pagados, tienen contratos leoninos y temporales; hasta el punto de que Ciudadanos en su campaña no ha dudado en apelar a las arcas del Estado para complementar los salarios; son generales los subsidios sostenidos por las comunidades autónomas y ayuntamientos y está sobre la mesa la renta básica; saben de ello los empresarios y los emigrantes relegados a reserva de mano de obra: trabajan en tareas rechazadas por los españoles por un salario menor (un $46 \%$ menos que el ingreso medio, aunque poco menos de la mitad lleva 15 años en España, según estudio de Cáritas con datos de 2017). Por inevitable recurso a la erudición, recordemos la persistencia de estas palabras: "siempre la pugna entre los pobres de oficio, itinerantes o estantes, y los empobrecidos a quienes con su trabajo no pueden alimentar y sostener a la familia"; las escribe Eugenio Larruga a finales del siglo XVIII.

Y los viejos jóvenes, los prejubilados y quienes no encuentran su lugar en las ciudades congestionadas y con alquileres prohibitivos. Unos trabajan en edificios modernos y en empresas boyantes, pero pagan alquileres usureros o viven en barrios que están en la senda de la degradación. Otros trabajan en oficios de servicios personales, comercio o transporte, pero viven en barrios de obreros y tienen que realizar largos desplazamientos diarios. Otros, libres para elegir lugar de residencia, no buscan vivienda en las ciudades medias o en las villas, aunque ahora disponen de servicios básicos quizá no tengan vida para ellos. Porque la España vacía, devenida en vaciada en esta fase, también incluye a la mitad de las capitales de provincia. El autor hace prestidigitación con el sistema económico y oculta una carta: el Estado está ahí para resolver los problemas; a esos ciudadanos siempre les queda el recurso a la protesta y a la reclamación; por tanto, mira para el cajón del dinero y no para la reivindicación laboral o la decisión personal.

La segunda oleada de la pandemia de covid-19 ha puesto de manifiesto desigualdades que diluyen las dicotomías territoriales definidas sintagmas y geografismos: cada cálculo acerca más el descenso del PIB al $20 \%$ en este 2020 o los servicios médicos son insuficientes después de años de vivir con lo justo o de privatizar, incluso falta personal, el mismo que encontraron formados gratis los sistemas sanitarios de Portugal o Gran Bretaña, por ejemplo. En la capital de las capitales españolas, la información publicada por El País el 17 y 20 de septiembre de 2020 muestra que la periferia está en la propia metrópoli: las autoridades han utilizado la zona básica de salud como criterio (entre 20.000 y 30.000 habitantes dependientes del mismo centro de salud) y han decretado el confinamiento en 37 porque el número de casos supera los 100 por 10.000, aunque cinco están 
por debajo para zonas de menor renta: todas están por debajo de los 13.000 euros de renta anual, son áreas con más emigrantes que trabajan en el centro de la metrópoli. ¡Y votan a la izquierda en una comunidad y ciudad gobernadas por la derecha!

Cuando corrijo estas notas en setiembre de 2020 la España vacía, como sintagma o geografismo que apelan al territorio, han quedado en suspenso: la epidemia ha devuelto el debate al equipamiento y a la gestión de los recursos; a las desigualdades sociales y laborales; a la modernización del sistema productivo y de la administración pública; y a la escala de vida, a la situación de los ciudadanos en sus barrios y en sus lugares de trabajo. A donde siempre estuvo. 
